\title{
Electron-Withdrawing Enhancement of Monomers Complexed with Alkylaluminum Halides
}

\author{
Hiroshi YabuUChI, ${ }^{*}$ Masaaki HiRooKa, ${ }^{* *}$ and Isao $\mathrm{KaETSU}^{\dagger}$ \\ Faculty of Science and Technology, Kinki University, \\ Kowakae, 3-4-1, Higashi-Osaka 577, Japan
}

(Received April 19, 1995)

\begin{abstract}
KEY WORDS Price-Alfrey's $Q-e$ value / Alternating Copolymerization / Diels-Alder Reaction / Electron-Withdrawing Enhancement / Alkylaluminum Halide / Methyl Acrylate /
\end{abstract}

The alternating copolymerization of donor monomers with acceptor monomers has been studied by several authors and recently reviewed. ${ }^{1}$ Alkylaluminum halides were found to be specifically effective in giving alternating copolymers of vinyl monomers having a low $e$-value in Price-Alfrey's $Q-e$ scheme (donor monomers: Group A) and conjugated vinyl monomers having a nitrile or carbonyl group (acceptor monomers: Group B) as shown in Table I. ${ }^{2-4}$

The reaction mechanism of the alternating copolymerization with an alkylaluminum halide has been proposed and discussed based on various experimental observations. ${ }^{5,6}$ It was suggested that in the course of the reaction the aluminum compound would play an important role by forming a complex with an acceptor monomer. The structures of the complexes can be drawn as (I) and (II). ${ }^{7-9}$

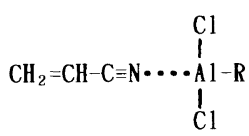

(I)

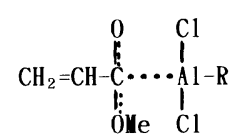

(II)
The electron density on the double bond of acceptor monomers might decrease noticeably due to the electron-withdrawing tendency of the aluminum compound leading to facilitate the alternating copolymerization.

The common method of measuring PriceAlfrey's $e$-value, which is considered to be a scale representing the electron-withdrawing tendency, does not seem to be applicable in alternating copolymerization since the monomer reactivity ratios $r_{1}$ and $r_{2}$ are essentially zero. A new method was therefore tried to estimate these values by measuring the rates of Diels-Alder reaction.

\section{EXPERIMENTAL}

\section{Materials}

Methyl acrylate (MA) was washed with an aqueous solution containing $5 \%$ sodium hydroxide and $20 \%$ sodium chloride, then with $20 \%$ aqueous sodium chloride. After cooling to $-78^{\circ} \mathrm{C}$ and separating ice, the monomer was dried over calcium chloride under nitrogen. It was distilled in vacuum and stored over calcium hydride.

\footnotetext{
† To whom correspondence should be addressed.

* Present address: Sumitomo Chemical Company, Ltd., 5-33, Kitahama 4-chome, Higashi-ku, Osaka 577, Japan.

** Present address: Faculty of Information Science, University of Marketing and Distribution Sciences, 3-1, Gakuen-Nishimachi, Nishi-ku, Kobe 673, Japan.
} 
Table I. Alternating copolymerization with alkylaluminum halides

\begin{tabular}{|c|c|c|c|c|c|c|c|c|c|c|c|}
\hline \multirow[b]{3}{*}{ No. } & \multicolumn{11}{|c|}{ Polymerization conditions } \\
\hline & \multicolumn{2}{|c|}{ Type of monomer $(\mathrm{amt}, \mathrm{g})^{\mathrm{a}}$} & \multirow{2}{*}{$\begin{array}{l}\text { Al compound } \\
\text { (amt, mmol) }\end{array}$} & \multirow{2}{*}{$\begin{array}{l}\text { Solvent } \\
(\mathrm{vol}, \mathrm{ml})\end{array}$} & \multirow{2}{*}{$\frac{\text { Temp }}{\left({ }^{\circ} \mathrm{C}\right)}$} & \multirow{2}{*}{$\frac{\text { Time }}{\mathrm{h}}$} & \multirow{2}{*}{$\frac{\text { Yield }}{\mathrm{gr}}$} & \multirow{2}{*}{$\frac{[\eta]^{\mathrm{c}}}{\mathrm{dlg^{-1 }}}$} & \multicolumn{3}{|c|}{ Analysis, Found $\left(\mathrm{Calcd}^{\mathrm{b}}\right)$} \\
\hline & Group A & Group B & & & & & & & $\mathrm{C}, \%$ & $\mathrm{H}, \%$ & $\mathrm{~N}, \%$ \\
\hline 1 & $\operatorname{Pr}(1500)$ & $\mathrm{AN}(30)$ & $\mathrm{AlEtCl}_{2}(574)$ & None & -78 & 0.5 & 20.8 & 3.00 & $\begin{array}{c}75.54 \\
(75.74)\end{array}$ & $\begin{array}{c}9.68 \\
(9.53)\end{array}$ & $\begin{array}{c}14.41 \\
(14.72)\end{array}$ \\
\hline 2 & $\operatorname{Pr}(100)$ & $\mathrm{AN}(2)$ & $\begin{array}{c}\mathrm{AlEt}_{1.5} \mathrm{Cl}_{1.5} \\
(50)\end{array}$ & None & -78 & 0.17 & 2.24 & 1.05 & - & - & 14.83 \\
\hline 3 & St (10) & MA (5.5) & $\begin{array}{l}\mathrm{AlEt}_{1.5} \mathrm{Cl}_{1.5} \\
\text { (16) }\end{array}$ & $\begin{array}{c}\text { Toluene } \\
\text { (133) }\end{array}$ & 25 & 5 & 2.55 & 2.88 & $\begin{array}{c}75.76 \\
(75.76)\end{array}$ & $\begin{array}{c}7.79 \\
(7.42)\end{array}$ & - \\
\hline 4 & St (15) & $\begin{array}{l}N \text {-n-Octyl } \\
\text { acrylamide } \\
(5)\end{array}$ & $\begin{array}{l}\mathrm{AlEt}_{1.5} \mathrm{Cl}_{1.5} \\
\quad(25)\end{array}$ & $\begin{array}{l}\text { Toluene } \\
\qquad(20)\end{array}$ & 25 & 22 & 2.13 & 0.95 & $\begin{array}{c}78.88 \\
(79.39)\end{array}$ & $\begin{array}{c}10.33 \\
(10.17)\end{array}$ & $\begin{array}{c}5.17 \\
(4.87)\end{array}$ \\
\hline 5 & St (5) & MMA (3.2) & $\begin{array}{l}\mathrm{AlEt}_{1.5} \mathrm{Cl}_{1.5} \\
(16)\end{array}$ & $\begin{array}{l}\text { Toluene } \\
\text { (61) }\end{array}$ & 25 & 5 & 1.54 & 2.02 & $\begin{array}{c}76.12 \\
(76.40)\end{array}$ & $\begin{array}{c}7.80 \\
(7.90)\end{array}$ & - \\
\hline 6 & St (5) & $\begin{array}{r}\text { Methacrylo- } \\
\text { nitrile (2.1) }\end{array}$ & $\begin{array}{l}\mathrm{AlEt}_{1.5} \mathrm{Cl}_{1.5} \\
(60)\end{array}$ & $\begin{array}{l}\text { Toluene } \\
\text { (60) }\end{array}$ & 25 & 18 & 0.36 & 0.54 & $\begin{array}{c}84.26 \\
(84.17)\end{array}$ & $\begin{array}{c}7.92 \\
(7.65)\end{array}$ & $\begin{array}{c}8.19 \\
(8.18)\end{array}$ \\
\hline
\end{tabular}

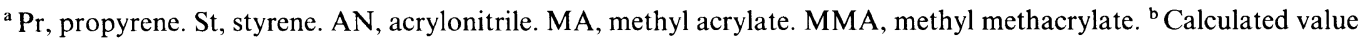
as an alternating copolymer. ${ }^{\mathrm{c}}$ Measured in benzene solution (No. 3, 4, and 5) and in dimethylformamide solution (No. 1,2 , and 6 ) at $30^{\circ} \mathrm{C}$.

Ethylaluminum dichloride, obtained from the Ethyl Corporation Ltd. was distilled under nitrogen atomosphere, diluted with purified toluene, and stored in glass amples. Aluminum tri-bromide was distilled with aluminumpacked column. bp $111^{\circ} \mathrm{C} / 8 \mathrm{mmHg}$.

Cyclopentadiene was prepared by thermal decomposition of dicyclopentadiene and then purified by distillation.

\section{Kinetic Constant Measurement}

All experiments to obtain kinetic constants were carried out in the same manner as was described by Sauer. ${ }^{10}$ The toluene solution of MA-Aluminum compound complexes (equimolar mixture) was prepared under nitrogen atmosphere at $-78^{\circ} \mathrm{C}$. Then the solution was brought to $20^{\circ} \mathrm{C}$. Upon the addition of cyclopentadiene the reaction rates were measured at the constant temperature of $20^{\circ} \mathrm{C}$. The concentration of the solution was selected in the range from $0.3 \mathrm{mmoll}^{-1}$ to $0.3 \mathrm{moll}^{-1}$ by taking the reaction rates into consideration.

\section{Copolymerization}

In a 200-ml four-necked flask equipped with a stirrer, a thermometer and a glass inlet tube, toluene and methyl acrylate were mixed under nitrogen atmosphere and cooled to $-78^{\circ} \mathrm{C}$. A toluene solution of ethylaluminum sesquichloride was added to this. Then the solution was brought to $25^{\circ} \mathrm{C}$. Upon the addition of styrene, polymerization reaction started. The copolymer was recovered by pouring the solution into a large amount of methanol and then the copolymer composition was analyzed.

\section{RESULTS AND DISCUSSION}

The kinetic data were expressed by the following equation (I) under the abovementioned experimental conditions.

$$
R_{\mathrm{DA}}=k \text { [cyclopentadiene][dienophile] }
$$

It was observed that a fairly good correlation existed between the $e$-values of dienophiles and the rate constants ${ }^{10}$ of Diels-Alder reaction of cyclopentadiene with the dienophiles as shown 
in Figure 1.

The rate constants of Diels-Alder reaction of cyclopentadiene with some complexed acceptor monomers or an original free monomer were evaluated as shown in Table II. The $e$-values of complexed acceptor monomers were estimated by using a good relation line based on the data in Figure I.

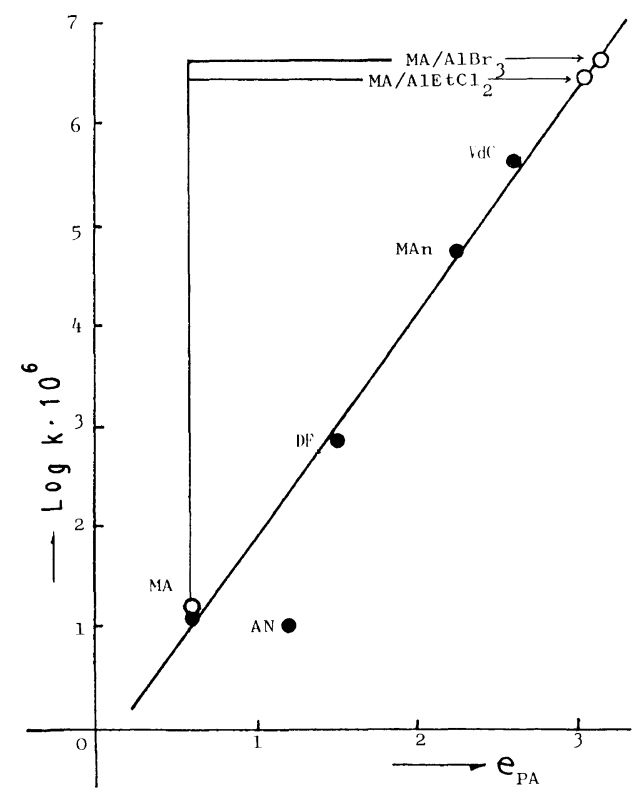

Figure 1. Kinetic constants $(k)$ of Diels-Alder reaction of cyclopentadiene with dienophiles vs. Price-Alfrey's $e$-values $\left(e_{\mathrm{PA}}\right) . \quad \mathrm{MA}$, methyl acrylate $\left(k=11.8 \times 10^{-6}\right.$ $\left.1 \mathrm{~mol}^{-1} \mathrm{~s}^{-1}, e_{\mathrm{PA}}=0.6\right) ; \mathrm{AN}$, acrylonitrile $\left(k=10.4 \times 10^{-6}\right.$ $\left.1 \mathrm{~mol}^{-1} \mathrm{~s}^{-1}, \varrho_{\mathrm{PA}}=1.20\right)$; DF, dimethyl fumarate $(k=742 \times$ $\left.10^{-6} 1 \mathrm{~mol}^{-1} \mathrm{~s}^{-1}, e_{\mathrm{PA}}=1.49\right)$; MAn, maleic anhydride $(k=$ $\left.55,600 \times 10^{-6} 1 \mathrm{~mol}^{-1} \mathrm{~s}^{-1}, \quad e_{\mathrm{PA}}=2.25\right) ; \quad \mathrm{VdC}$, vinylidene cyanide $\left(k=455,000 \times 10^{-6} \mathrm{~mol}^{-1} \mathrm{~s}^{-1}, e_{\mathrm{PA}}=2.58\right) . k$ is cited from the ref 10 .
The $e$-value of $\mathrm{MA} / \mathrm{AlEtCl}_{2}$ complex estimated by this Diels-Alder method was found to be 3.05 , which is substantially larger than that of the original free methyl acrylate monomer of 0.6 . When the monomer reactivity ratios $r_{1}$ and $r_{2}$ represent certain amount of values in the copolymerization, the $e$-value of monomer-metal compound complexes could be measured by the copolymerization method. Based on this method the increase of $e$-values by forming a complex was observed in several cases, in which some degree of alternating tendency of the complexed monomers was recognized. The $e$-value of ethyl acrylate- $\mathrm{SnCl}_{4}$ complex was reported to be 1.92 which is larger than that of free ethyl acrylate monomer of 1.02. ${ }^{11}$ When these values and the alternating tendency are taken into consideration the estimated $e$-value of 3.05 of $\mathrm{MA}-\mathrm{AlEtCl}_{2}$ seems to be reasonable and the validity of the value would be proved by the following calculation and the copolymerization results.

Refering to the $Q-e$ scheme, the following relations hold:

$$
\begin{aligned}
& r_{1}=Q_{1} / Q_{2} \cdot \exp \left\{-e_{1}\left(e_{1}-e_{2}\right)\right\} \\
& r_{2}=Q_{2} / Q_{1} \cdot \exp \left\{-e_{2}\left(e_{2}-e_{1}\right)\right\}
\end{aligned}
$$

Then,

$$
r_{1} r_{2}=\exp \left\{-\left(e_{1}-e_{2}\right)_{2}\right\}
$$

From eq 3, it is recognized that as for the alternating copolymer the difference of $e$-values between two monomers is required to be large. Therefore, it may be theoretically understood

\begin{tabular}{|c|c|c|c|c|c|}
\hline No. & $\begin{array}{c}\text { Dienophile } \\
\text { (concentration) }\end{array}$ & Solvent & $\frac{k \times 10^{6}}{1 \mathrm{~mol}^{-1} \mathrm{~s}^{-1}}$ & $\log k \times 10^{6}$ & $\begin{array}{c}e_{\mathrm{PA}}{ }^{\mathrm{a}} \\
\text { (extraporated) }\end{array}$ \\
\hline 1 & $\mathrm{MA}\left(0.3 \mathrm{moll}^{-1}\right)$ & Toluene & 15.3 & 1.18 & 0.60 \\
\hline 2 & $\mathrm{MA}-\mathrm{AlBr}_{3}\left(0.3 \mathrm{mmoll}^{-1}\right)$ & Toluene & $4,420,000$ & 6.65 & $(3.12)$ \\
\hline 3 & $\mathrm{MA}-\mathrm{AlEtCl}_{2}\left(1.5 \mathrm{mmoll}^{-1}\right)$ & Toluene & $3,010,000$ & 6.48 & $(3.05)$ \\
\hline
\end{tabular}

Table II. Diels-Alder reaction of cyclopentadiene with MA and MA-Aluminum compound complexes (equimolar complex) in toluene at $20^{\circ} \mathrm{C}$

a Price-Alfrey's $e$-value extraporated from the line of Figure 1. 
that if the $e$-value of a monomer is enhanced by forming a complex, the alternating tendency is to be raised.

The $r_{1} r_{2}$ value of the copolymerization of styrene (St) and methyl acrylate (MA) complexed with an alkylaluminum halide would be evaluated in the following manner: The $e$-values of $\mathrm{St}, \mathrm{MA}$, and $\mathrm{MA}-\mathrm{AlEtCl}_{2}$ are $-0.8,0.6$, and 3.05 , respectively. Then the $r_{1} r_{2}$ value of $\mathrm{St}-\mathrm{MA}-\mathrm{AlEtCl}_{2}$ copolymerization is calculated to be $3.6 \times 10^{-7}$ from eq 3 , whereas the $r_{1} r_{2}$ value of $\mathrm{St}-\mathrm{MA}$ copolymerization is 0.14 . The alternating tendency is therefore reasonably expected in the copolymerization

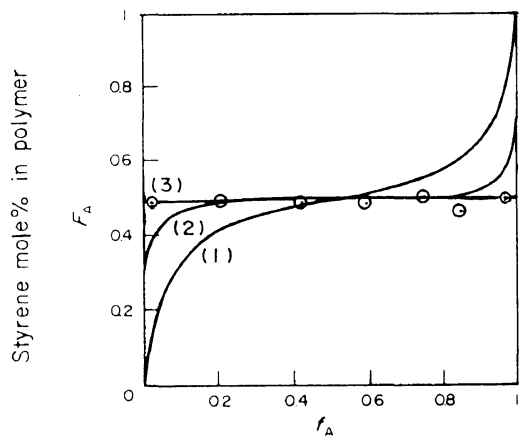

Styrene mole \% in monomers

Figure 2. Copolymer mole fraction $\left(F_{\mathrm{A}}\right)$ of monomer $M_{\mathrm{A}}$ against its mole fraction in the feed $\left(f_{\mathrm{A}}\right)$. (1) theoretical line, $r_{\mathrm{A}} r_{\mathrm{B}}=1 \times 10^{-2} \quad\left(r_{\mathrm{A}}=r_{\mathrm{B}}=0.1\right)$; (2) theoretical line: $r_{\mathrm{A}} r_{\mathrm{B}}=1 \times 10^{-4}\left(r_{\mathrm{A}}=r_{\mathrm{B}}=0.01\right)$; (3) $(-\odot-) \mathrm{St}-\mathrm{MA}-$ $\mathrm{AlEt}_{1.5} \mathrm{Cl}_{1.5}$ complexed copolymerization. Polymerization condition: $25^{\circ} \mathrm{C}$, solvent toluene, $[\mathrm{MA}] /[\mathrm{St}]$ variable, $[\mathrm{MA}] /\left[\mathrm{AlEt}_{1.5} \mathrm{Cl}_{1.5}\right]=2$. of St-MA-AlEtCl 2 . As it is shown in Figure 2 , the relationship between monomer feed and polymer composition in the St-MA$\mathrm{AlEt}_{1.5} \mathrm{Cl}_{1.5}$ complexed copolymerization clearly coincided with the theoretical line in case of $r_{1} r_{2}=$ essentially zero.

The observation of the electron-withdrawing enhancement by forming a complex would lead to an explicit explanation of the alternating tendency of the complexed copolymerization.

\section{REFERENCES}

1. J. M. Cowie, Comprehensive Polym. Sci., 4, 377 (1989).

2. M. Hirooka, H. Yabuuchi, S. Morita, S. Kawasumi, and K. Nakaguchi, J. Polym. Sci., B, 5, 47 (1967).

3. M. Hirooka, H. Yabuuchi, J. Iseki, and Y. Nakai, J. Polym. Sci., A-I, 6, 1381 (1968).

4. M. Hirooka, H. Yabuuchi, S. Kawasumi, and K. Nakaguchi, J. Polym. Sci., Polym. Chem. Ed., 11, 1281 (1973).

5. M. Hirooka, J. Polym. Sci., Polym. Lett. Ed., 10, 171 (1972).

6. M. Hirooka, Pure Appl. Chem., 53, 681 (1981).

7. J. Furukawa, E. Kobayashi, S. Nagata, and T. Moritani, J. Polym. Sci., Polym. Chem. Ed., 12, 1799 (1974).

8. H. Hirai and H. Komiyama, J. Polym. Sci., Polym. Chem. Ed., 12, 2701 (1974).

9. Y. Komo, S. Kondo, and K. Iimura, J. Polym. Sci., Polym. Lett. Ed., 12, 153 (1974).

10. J. Sauer, H. Wiest, and A. Mielert, Chem. Ber., 97, 3183 (1964).

11. B. Yamada, Y. Kusuki, and T. Otsu, Makromol. Chem., 137, 29 (1970). 